\title{
Control of meadowsweet Filipendula ulmaria through a change of management from grazing to mowing at an English floodplain meadow.
}

\author{
Laura George $^{1 *}$, Emma C. Rothero ${ }^{1}$, Irina Tatarenko ${ }^{1}$, Hilary Wallace $^{2}$, Mike Dodd $^{1}$, Nancy Reed $^{3}$, Andy Fleckney $^{3}$, \\ Graham Bellamy ${ }^{3}$ \& David Gowing ${ }^{1}$ \\ ${ }^{1}$ School of Environment, Earth and Ecosystem Sciences, The Open University, Walton Hall, Milton Keynes, MK7 6AA \\ 2 Ecological Surveys (Bangor), The Old School House, Canon Pyon, Hereford, HR4 8PF \\ ${ }^{3}$ Bedfordshire, Cambridgeshire and Northamptonshire (BCN) Wildlife Trust, The Visitor Centre, Priory Country Park, Barkers Lane, \\ Bedford, MK41 9DJ
}

\section{SUMMARY}

DOI: https://doi.org/10.52201/CEJ18HFGL5629

Floodplain meadow grassland is a diverse habitat which has become increasingly rare throughout Europe. Meadowsweet Filipendula ulmaria, is a characteristic species of its plant community, however it can become overly dominant in the sward resulting in detrimental effects on the community as a whole. High abundance can reduce both the diversity of the sward, by shading out low growing species, and the quality of the hay crop.

An eight-year management trial (2011-2019) was undertaken at Fancott Woods and Meadows SSSI by the BCN Wildlife Trust and the Floodplain Meadows Partnership, to test whether it was possible to reduce the dominance of meadowsweet through an annual hay cut with aftermath grazing instead of grazing management only, across three blocks of experimental treatments. A secondary aim of the trial was to investigate whether a change in management could also increase the plant-species diversity. Three plots were cut in June and then aftermath grazed, compared to three control plots that were only grazed from July onwards. The study found that cover of meadowsweet decreased from 55\% to $6 \%$ under the annual cut and aftermath grazing treatment compared to a decrease from $58 \%$ to $35 \%$ in the control (grazed only) areas. This was accompanied by an increase in plant-species diversity in the cut areas compared to control plots. The study concluded that annual cutting can be used to control coarse and dominant meadowsweet effectively, and that cutting followed by aftermath grazing in a floodplain meadow delivers greater botanical diversity compared to grazing alone.

\section{BACKGROUND}

Species-rich floodplain meadows, classically described as the Sanguisorba officinalis - Alopecurus pratensis Burnet floodplain meadow (coded MG4 in the National Vegetation Classification, Rodwell 1992) are rare in the UK. Less than 1200 ha remain (Rothero et al. 2016), and they are listed under the European Habitats Directive as the Annex 1 habitat (6510) Lowland Meadows (European Community, 1992). The community is sustained by traditional management, typically an annual hay cut followed by aftermath (i.e. post-harvest) grazing.

The benefits of cutting and removing plant material from a site are two-fold, (i) it reduces the build-up of nutrients in the system, which favours more dominant competitor species, and (ii) prevents the formation of a thick litter layer which inhibits the germination and growth of smaller, less competitive species (Opdekamp et al. 2012). Therefore, the cessation of mowing can lead to a reduction in species richness and a shift in community composition benefiting dominant competitor species (Diemer et al. 2001, Pavlů et al. 2011). Alterations to the hydrology of a site can further compound any issues in relation to management. Plant species have different hydrological requirements, defined as 'niches', and therefore any changes in soil moisture can lead to a shift in plant community composition (Silvertown et al. 1999).

\footnotetext{
*corresponding author: laura.george1@open.ac.uk
}

Meadowsweet Filipendula ulmaria is a typical component of the sward of an MG4 (National Vegetation Classification) grassland, but in certain conditions it can become dominant and difficult for site managers to control. F. ulmaria thrives in highly productive wet meadows (Neunkamp et al. 2013) and it can spread rapidly by rhizomatous growth when neither grazed nor mown (Grime et al. 1990). Therefore, reduced management intensity combined with wetter than usual weather conditions can result in the dominance of this tall species, in turn leading to a reduction in species diversity and poor-quality hay (Rothero et al. 2016).

There are eight studies in the Conservation Evidence database that have been undertaken on fens and fen meadows in the UK, Belgium, Switzerland, Germany, the Czech Republic and Poland that found that mowing increased plant-species richness compared to: (i) no mowing (Gryseels, 1989a, Diemer et al. 2001, Billeter et al. 2007, Opdekamp et al. 2012), (ii) before mowing (Rowell et al. 1985, Gryseels, 1989b, Hájkova et al. 2009), or (iii) before grazing (Stammel et al. 2003). However, there are no studies, in Conservation Evidence, that looked at a similar comparison for floodplain meadows, or looked at mowing as a control mechanism for meadowsweet. Therefore, the aim of this study was to assess the effectiveness of a June hay cut in suppressing the dominance of meadowsweet and promoting species diversity when compared to continuing the "grazing only" management. 


\section{ACTION}

\section{Study site}

Fancott Woods and Meadows Site of Special Scientific Interest (SSSI) (Figure 1) is situated on the floodplain of the River Flit in Bedfordshire, UK (NGR TL 025274; Lat/Long 51.935679, -0.51047879) and has been owned by the Bedfordshire, Cambridgeshire and Northamptonshire (BCN) Wildlife Trust since May 2007. The site overlies chalky boulder clay and thus there is some calcareous influence in the groundwater supply. The site comprises two grassland fields (northern and southern) and a wooded area.

The study area lies within the northern field (Figure 1), which has not been cut for hay since before 2007. The previous owner had practised traditional meadow management at the site, until they were unable to undertake the cut so began to manage the site with grazing only. When the BCN Wildlife Trust took ownership of the site, the northern field continued to be managed by grazing rather than cutting, with the site being grazed by cattle from July at approximately one animal per hectare for four months.

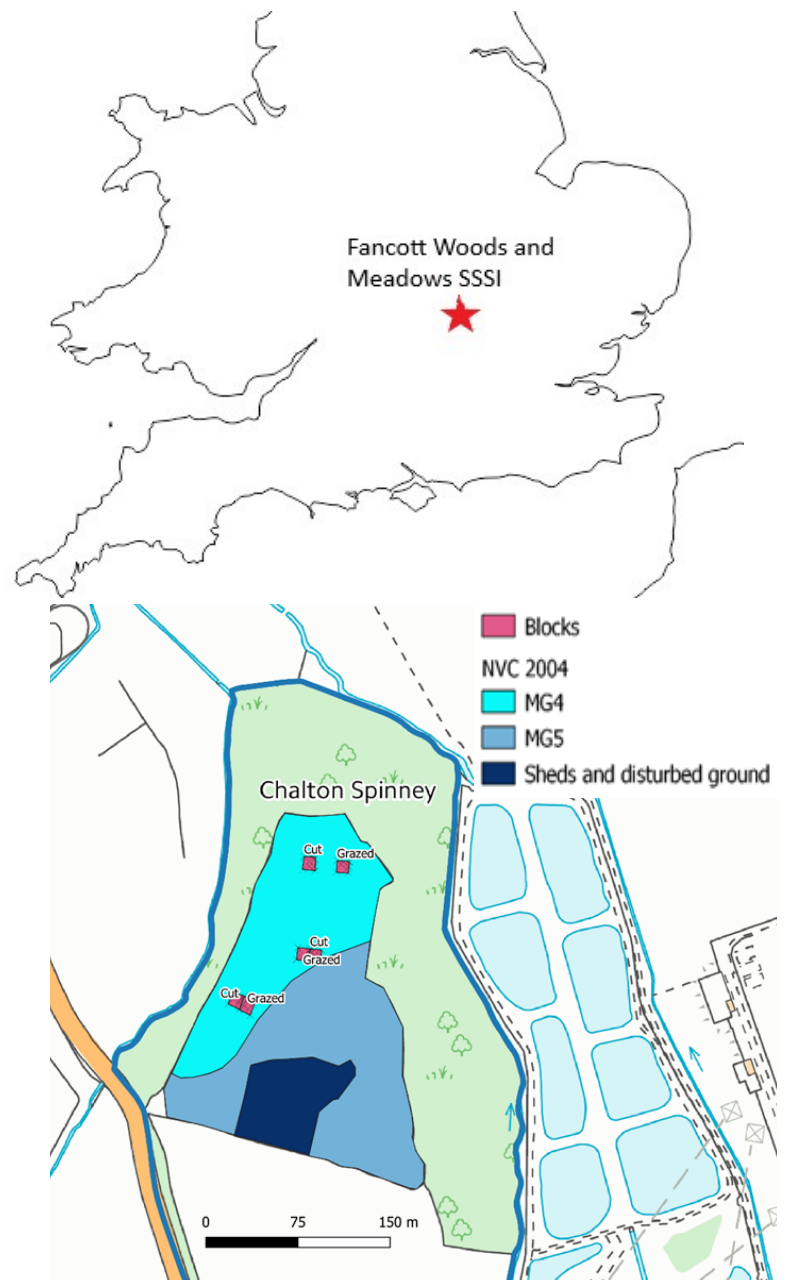

Figure 1. Location of Fancott Woods and Meadows SSSI in south-east England, UK (top); and distribution of plant communities in the northern field, showing location of experimental blocks. Based on data from Pankhurst (2004).

(C) Crown Copyright and Database Right (2018) OS

(Digimap Licence)
In 2004, the plant community in the northern field was mapped (Pankhurst, 2004) following the National Vegetation Classification (Rodwell, 1992) and described as typical MG4 vegetation, albeit rather species-poor to the west, grading into drier vegetation towards the east with clear calcareous influences, best classified as the MG5 Cynosurus cristatus Centaurea nigra vegetation community (Figure 1, Pankhurst, 2004). In 2010 it was noted that meadowsweet Filipendula ulmaria had become dominant in the northern field, suppressing less competitive species. It is believed that this substantial expansion in meadowsweet cover was related to the unusually wet summers of 2007-2009.

\section{Data collection}

A replicated, controlled management trial was established in 2011 to investigate the effect on plantcommunity composition following the reintroduction of a regular cutting regime as a method for controlling meadowsweet. Three experimental blocks (20 m x 10 $\mathrm{m})$ were established in the northern field (Figure 1). The blocks were all located within the area categorised by Pankhurst (2004) as MG4 and plotted using a real-time differentiating global positioning system (dGPS, RX1200, Leica, Switzerland). This device is accurate to $10 \mathrm{~mm}$ for both horizontal distances and surface elevation. The same plot areas were located each year using the dGPS and marked out with canes.

Each block comprised two plots: a cut treatment; and an uncut control area (Figure 1). There is a gap between the cut and uncut plots in the most northerly block (Figure 1); this was done to exclude an area of trampled, and therefore unrepresentative, vegetation resulting from a pathway. Volunteers from the $\mathrm{BCN}$ Wildlife Trust cut the plots marked as 'cut' using a brushcutter with a triangular blade attachment. The cut plots were mown in mid-June each year and the cut material was raked up and removed from the plot. They were then grazed along with the uncut control areas. All markers were removed before stock were turned out onto the site. The uncut control plots were managed by grazing alone, with cattle being introduced from July onwards.

In 2011, five quadrats, each $1 \mathrm{~m} \times 1 \mathrm{~m}$, were randomly placed within each plot and positions fixed using the dGPS. All botanical data were collected prior to the annual hay cut, with baseline data collected in June 2011 and the first post-treatment survey undertaken in June 2012. Subsequent surveys were carried out in June 2013, 2015, 2018 and 2019. In each monitoring year, the same quadrat locations were marked out, using the dGPS, and surveyed to compare to the 2011 baseline data. All rooted species of vascular plant and bryophyte were recorded within each quadrat together with a visual estimate of projected cover (i.e. percentage cover; hereafter called abundance). 


\section{Data analysis}

All data manipulation and analyses were carried out using R (R Core Team 2013) and Excel (Microsoft 2013). Species diversity (Shannon-Weiner index) was calculated for each of the 30 samples using the abundance data for each of the species recorded. The Shapiro-Wilk test and QQ-plots were used to test for normality in the plant species abundance and diversity data; the data were normally distributed.

Linear mixed effect (lme) models were fitted using the package 'Ime4' (Bates et al. 2014); F. ulmaria abundance and species diversity were the dependent variables, with treatment and time (year) as fixed factors and block as a random factor. The anova function in the R package 'ImerTest' (Kuznetsova et al. 2014) was used to produce the p-values, in order to evaluate the effect of treatment (i.e. cut and control) over time (2011-2019) on F. ulmaria abundance and on species diversity (using average values from plots). The effect of treatment was analysed at each time point (i.e. year) using a post-hoc pairwise t-test; pvalues were adjusted using the Bonferroni multipletesting correction method.

Alongside $F$. ulmaria, eight other plant species were selected for further analysis because they exhibited: (i) a substantial increase in overall abundance ( $>8 \%$ ) between 2011 and 2019, and/or ii) a marked difference $(>7 \%)$ in abundance between the control and cut plots. The complete species dataset is available on request. The overall change in abundance for these eight species was calculated by subtracting average abundance in 2019 from the equivalent value from 2011. Average abundance of each species was plotted to show the overall change between 2011 and 2019 in the cut and control plots, and the difference in abundance between the two treatments.

Generalised linear modelling was used to explore the relationship between species diversity and $F$. ulmaria abundance, using data from individual quadrats across all survey years $(n=180)$. A first order polynomial was used to generate a line of best fit in the scatter plot and a linear model was then run to calculate the significance of the relationship (p-value) and the amount of variation explained $\left(\mathrm{R}^{2}\right)$.

\section{CONSEQUENCES}

From 2013 to 2019 there was a consistent decline in F. ulmaria abundance in the cut plots and, after an initial increase, there was also a decline in the control plots (Figure 2). The greater decline in meadowsweet abundance was in the cut treatment from 55\% in 2011 to $6 \%$ in 2019 , compared to $58 \%$ down to $35 \%$ in the control plots. There was a steady increase in species diversity between 2013 and 2019 in the cut plots, and after an initial decline in the control plots there was an upwards trend in diversity from 2015 onwards (Figure 3 ). The increase in species diversity was greater in the cut treatment compared to the control.

There was a statistically significant interaction between the different management types (cut versus control treatments) and time (year) on both $F$. ulmaria abundance and species diversity (both $\mathrm{p}<0.001$; Table 1). The effect of treatment on $F$. ulmaria abundance and species diversity was significant in 2015, 2018 and 2019, but not earlier (i.e. 2012 or 2013; Table 2).

There was a significant negative relationship $(\mathrm{p}<$ 0.001 ) between species diversity and $F$. ulmaria abundance across the duration of the experiment (Figure 4). The linear model applied suggests the majority of the variation in species diversity (72\%) could be explained by the abundance of $F$. ulmaria. Five species increased their abundance by $8 \%$ or more in the cut treatment between 2011 and 2019 (Figure 5). Three species performed better in the control treatment: two grass species (Yorkshire fog Holcus lanatus and rough-stalked meadow-grass Poa trivialis) and one herb, creeping Jenny Lysimachia nummularia.

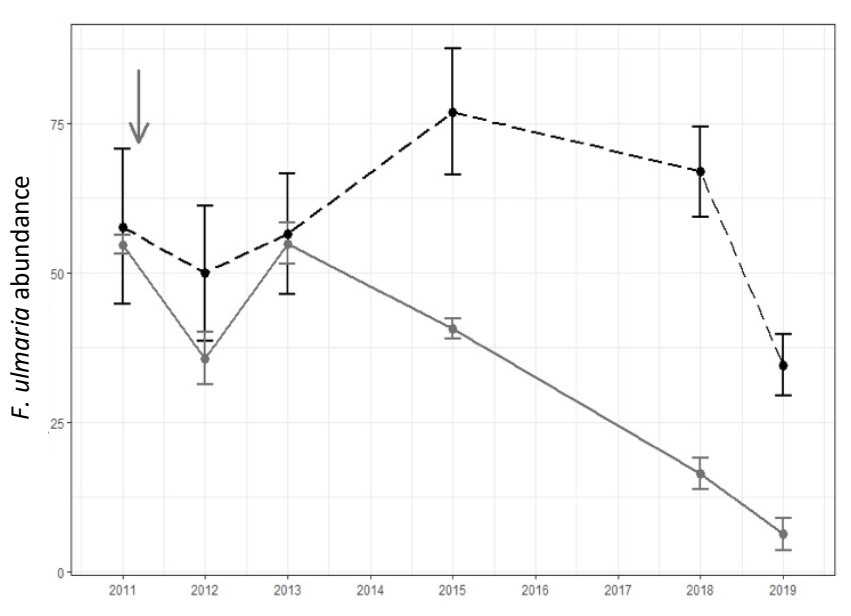

Figure 2. Change in the abundance (percentage projected cover) of meadowsweet Filipendula ulmaria in cut (grey) and control (black dashed) plots between 2011 and 2019; the arrow denotes when the treatments were first imposed (following the baseline botanical survey in June 2011). Values are means ( $n=3$ for each year) and bars are one standard error of the mean.

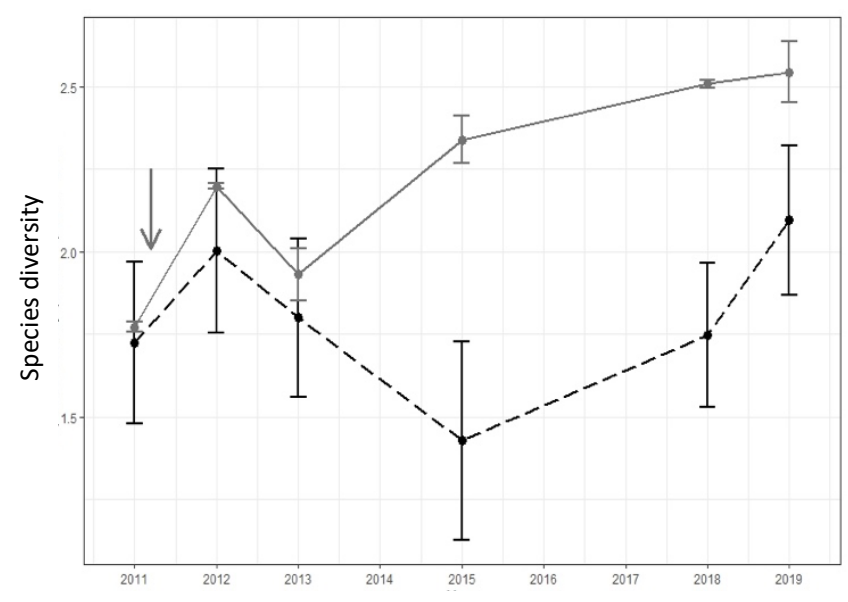

Figure 3. Change in species diversity (Shannon) in cut (grey) and control (black dashed) plots between 2011 and 2019; the arrow denotes when the treatments were first imposed (following the baseline botanical survey in June 2011). Values are plot means $(n=3$ for each year) and bars are one standard error of the mean. 
L. George, E.C. Rothero, I. Tatarenko, H. Wallace, M. Dodd, N. Reed, A. Fleckney, G. Bellamy \& D. Gowing / Conservation Evidence Journal (2021) 18, 44-49

Table 1. Results of the linear mixed effect models evaluating the effect of different management treatments over time on Filipendula ulmaria abundance and species diversity.

\begin{tabular}{llllllllll}
\hline & \multicolumn{3}{c}{ Filipendula ulmaria abundance } & \multicolumn{4}{c}{ Species diversity (Shannon) } \\
\hline Effect & DFn & DFd & F & $\mathrm{p}$ & DFn & DFd & F & $\mathrm{p}$ \\
\hline Treatment & 1 & 174 & 18.26 & $<0.001$ & 1 & 174 & 12.21 & $<0.001$ \\
Year & 1 & 174 & 32.07 & $<0.001$ & 1 & 174 & 22.95 & $<0.001$ \\
Treatment:Year & 1 & 174 & 18.35 & $<0.001$ & 1 & 174 & 12.28 & $<0.001$ \\
\hline
\end{tabular}

Table 2. Results (p-values only) of the post-hoc pairwise t-test evaluating the effect of the management treatment at each time point (i.e. year) on Filipendula ulmaria abundance and species diversity.

\begin{tabular}{lcc}
\hline Year & Filipendula ulmaria abundance & Species diversity (Shannon) \\
\hline 2011 & 0.76 & 0.83 \\
2012 & 0.15 & 0.26 \\
2013 & 0.86 & 0.46 \\
2015 & 0.001 & $<0.001$ \\
2018 & $<0.001$ & $<0.001$ \\
2019 & $<0.001$ & 0.002 \\
\hline
\end{tabular}

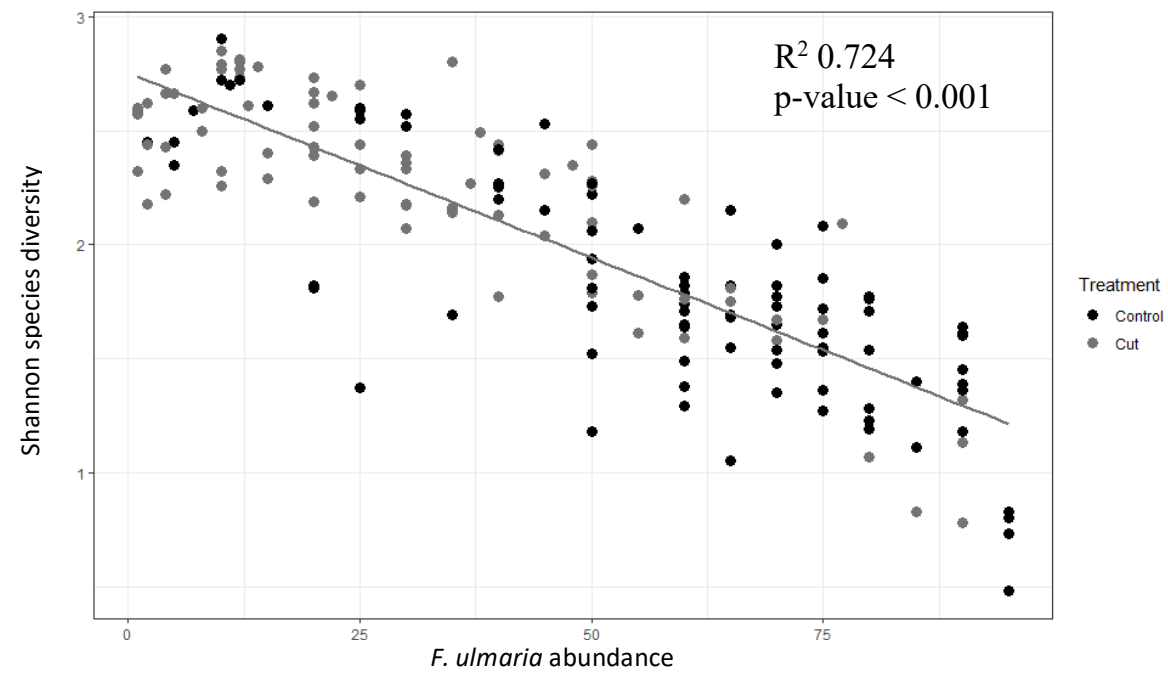

Figure 4. Relationship between the Shannon Diversity Index of individual $1 \mathrm{~m} \mathrm{x} 1 \mathrm{~m}$ quadrats and the abundance of Filipendula ulmaria in that quadrat (both treatments) across all survey years $(\mathrm{n}=180)$.
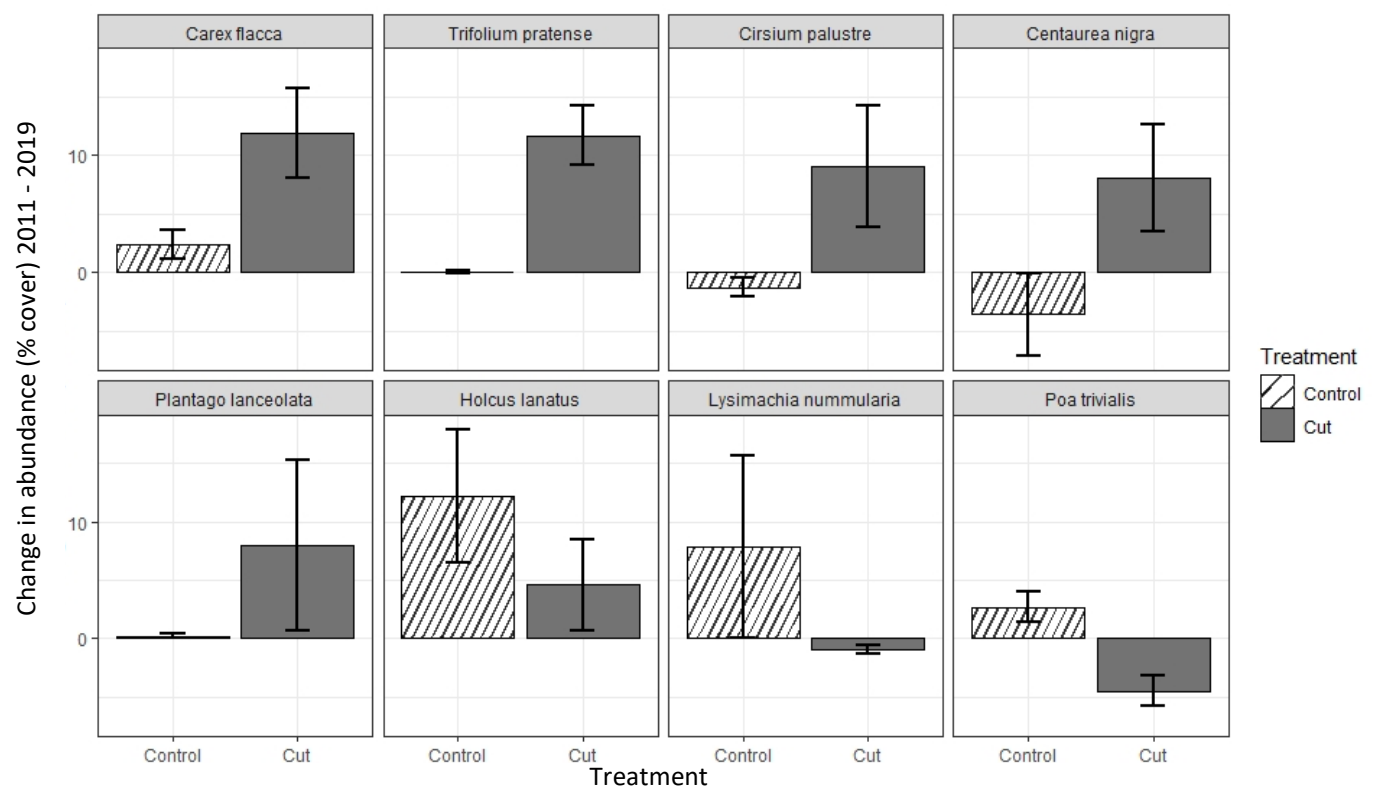

Figure 5. Changes in the mean abundance of eight selected species in cut and control plots between 2011 and 2019. Change in abundance for each species was calculated by averaging the abundance across the five quadrats of each plot in 2019 and subtracting it from the equivalent sum for $2011(\mathrm{n}=3)$. 


\section{DISCUSSION}

The results of this study show that the application of cutting, in addition to aftermath grazing, is an effective management tool for suppressing the growth of meadowsweet Filipendula ulmaria on a floodplain meadow. The effect of treatment on meadowsweet abundance was significant from 2015 to 2019 , which suggests that this method of control required four years to elicit the desired effect (i.e. a significant decline in meadowsweet abundance). After an initial increase in F. ulmaria abundance in the control plots, there was also an overall reduction in the dominance of meadowsweet in these plots. These fluctuations are likely due to soil moisture status, 2012 had a particularly wet summer whereas 2018 was particularly dry. The suppression of meadowsweet by 2019 (after eight years of treatment) was striking in the cut plots, with only $6 \%$ abundance compared to $35 \%$ in the control plots.

Between 2011 and 2019, there was an overall increase in species diversity across all the plots, but the greatest improvement was in the cut treatment. Additionally, there was a significant negative relationship between meadowsweet abundance and species diversity, where high levels of diversity coincided with lower meadowsweet abundance. These findings suggest that the suppression of $F$. ulmaria can lead to an increase in plant-species diversity. The findings of this study are in agreement with similar studies held in the Conservation Evidence database, that found mowing increased plant-species richness compared to not mowing (e.g. Billeter et al. 2007, Opdekamp et al. 2012).

Changes in the abundance of other species occurred in the cut and control plots between 2011 and 2019; with eight species being particularly noteworthy. There was an increase in the abundance of four species of forb (non-graminoid herbaceous flowering plants) and Carex flacca (glaucous sedge) in the cut plots, whereas, in the control plots, there was an increase in two species of competitive grass and in Lysimachia nummularia (creeping Jenny).

An increase in light levels, as a result of reduced meadowsweet dominance, could explain changes in species abundances. L. nummularia grows at ground level and is shade-tolerant (Ellenberg light value 4; Ellenberg, 1988); whereas the more light-demanding herb Centaurea nigra (Ellenberg light value 7) declined in the control treatments yet increased in the cut plots. High abundance of meadowsweet may potentially shade out typical meadow herbs, such as C. nigra, but create a niche for L. nummularia.

The overall reduction in meadowsweet, and the concurrent increase in species diversity, across the northern field, even in the control treatment, is assumed to be a result of the site's hydrology returning to 'normal' following three wet summers (20072009). These wet summers may have been the driver of the rapid expansion of meadowsweet at Fancott SSSI, as $F$. ulmaria thrives in highly productive wet meadows (Neunkamp et al. 2013).

In conclusion, the reintroduction of hay cutting in the northern field has shown a decline in the dominance of meadowsweet and an increase in species diversity. We have shown that hay cutting, as opposed to grazing alone, can be an effective management tool for the control of meadowsweet in floodplain meadows. In order to restore greater species diversity, it is recommended that an annual hay cut is established across the area. Hay cutting should typically be carried out in June when weather conditions allow (Rothero et al. 2016). However, there may be site specific reasons why timing needs to be adjusted, such as stipulations under agrienvironment schemes, the presence of protected species, or unsuitable ground conditions (if the site is too wet, machinery should not be used as it may cause soil compaction).

\section{ACKNOWLEDGEMENTS}

The BCN Wildlife Trust undertook the experimental management of the plots over the period of the study and Mrs Rachel Webb kindly funded the analysis of the data.

\section{REFERENCES}

Bates, D., Maechler, M., Bolker, B. and Walker, S. (2014) lme4: linear mixed-effects models using Eigen S4., R package version 1.1-7. Available at: https://cran.rproject.org/web/packages/lme4/index.html (Accessed: 1 April 2021).

Billeter R., Peintinger M. \& Diemer M. (2007) Restoration of montane fen meadows by mowing remains possible after 4-35 years of abandonment. Botanica Helvetica, 117, 1-13. https://doi.org/10.1007/s00035-007-0743-9

Diemer M., Oetiker K. \& Billeter R. (2001) Abandonment alters community composition and canopy structure of Swiss calcareous fens. Applied Vegetation Science, 4(2), 237-246. https://doi.org/10.1111/j.1654109x.2001.tb00492.x

Ellenberg H. (1988) Vegetation ecology of Central Europe. Fourth Edition. Cambridge University Press, Cambridge.

European Community (1992) Council Directive 92/43/EEC on the conservation of natural habitats and of wild fauna and flora. Official Journal no. L 206, 22.07.1992

Grime J.P., Hodgson J.G. \& Hunt R. (1988) Comparative Plant Ecology: A functional approach to common British species. Unwin Hyman Ltd., London

Gryseels M. (1989a) Nature management experiments in a derelict reedmarsh. I: effects of winter cutting. Biological Conservation, 47, 171-193. https://doi.org/10.1016/0006-3207(89)90063-3

Gryseels M. (1989b) Nature management experiments in a derelict reedmarsh. II: effects of summer mowing. Biological Conservation, 48, 85-99. https://doi.org/10.1016/0006-3207(89)90028-1

Hájkova P., Hájek M. \& Kintrová K. (2009) How can we effectively restore species richness and natural composition of a Molinia invaded fen? Journal of 
L. George, E.C. Rothero, I. Tatarenko, H. Wallace, M. Dodd, N. Reed, A. Fleckney, G. Bellamy \& D. Gowing / Conservation Evidence Journal (2021) 18, 44-49

Applied Ecology, 46, 417-425. https://doi.org/10.1111/j.13652664.2009.01608.x

Kuznetsova, A., Brockhoff, P. B. and Christianson, R. H. B. (2014) lmerTest: tests for random and fixed effects for linear mixed effect models, $\mathrm{R}$ package version 2.0-11. Available at: https://cran.rproject.org/web/packages/lmerTest/index.html (Accessed: 1 April 2021)

Neuenkamp L., Metsoja J.A., Zobel M. \& Hölzel N. (2013) Impact of management on biodiversitybiomass relations in Estonian flooded meadows. Plant ecology, 214(6), 845-856. https://doi.org/10.1007/s11258-013-0213-y

Opdekamp W., Beauchard O., Backx H., Franken F., Cox T.J.S., Van Diggelen R. \& Meire P. (2012) Effects of mowing cessation and hydrology on plant trait distribution in natural fen meadows. Acta Oecologica, 39, 117-127. https://doi.org/10.1016/j.actao.2012.01.011

Pankhurst T. (2004) NVC Survey of Fancott Woods and Meadows SSSI. Bugle Ecological Services

Pavlů L., Pavlů V., Gaisler J., Hejcman M. \& Mikulka J. (2011) Effect of long-term cutting versus abandonment on the vegetation of a mountain hay meadow (Polygono-Trisetion) in Central Europe. Flora-Morphology, Distribution, Functional Ecology of Plants, 206(12), 1020-1029. https://doi.org/10.1016/j.flora.2011.07.008
Rodwell J.S. (1992) British plant communities. Volume 3. Grasslands and montane communities. Cambridge University Press, Cambridge

R Core Team (2013) R: A language and environment for statistical computing, Vienna, Austria: R Foundation for Statistical Computing. https://www.r-project.org/ (accessed 1 April 2020)

Rothero E., Lake S. \& Gowing D.J. (2016) Floodplain Meadows - Beauty and Utility A Technical Handbook. Floodplain Meadows Partnership, Milton Keynes

Rowell T.A., Guarino L., \& Harvey H.J. (1985) The experimental management of vegetation at Wicken Fen, Cambridgeshire. Journal of Applied Ecology, 22, 217-227. https://doi.org/10.2307/2403339

Silvertown J., Dodd M., Gowing D.J. \& Mountford J.O. (1999) Hydrologically defined niches reveal basis for species richness in plant communities, Nature, 400, 61-63. https://doi.org/10.1038/21877

Stammel B., Kiehl K. \& Pfadenhauer J. (2003) Alternative management on fens, response of vegetation to grazing and mowing. Applied Vegetation Science, 6, 245-254. https://doi.org/10.1111/j.1654109x.2003.tb00585.x

The Conservation Evidence Journal is an open access online journal devoted to publishing the evidence on the effectiveness of management interventions. The other papers from The Conservation Evidence Journal are available from www.conservationevidencejournal.com. The pdf is free to circulate or add to other websites and is licensed under the Creative Commons Attribution 4.0 International License http://creativecommons.org/licenses/by/4.0/. Under this licence, authors retain ownership of the copyright for their articles. 